\title{
Improving Adherence to Topical Medication in Patients with Glaucoma
}

\author{
Ian Tapply (D) ${ }^{1,2}$ \\ David C Broadway ${ }^{1,3}$ \\ 'Department of Ophthalmology, Norfolk \\ and Norwich University Hospital, \\ Norwich, NR4 7UY, UK; ${ }^{2}$ Department of \\ Ophthalmology, Addenbrooke's Hospital, \\ Cambridge, CB2 0QQ, UK; ${ }^{3}$ School of \\ Pharmacy, University of East Anglia, \\ Norwich, NR4 7T], UK
}

\begin{abstract}
The glaucomas form a heterogenous group of conditions, which collectively account for one of the most common irreversible causes of blindness worldwide. The only treatment, for which there is evidence, to stop or slow glaucomatous disease progression is to lower intraocular pressure (IOP); this is most often initially achieved with topical medication. Adherence to anti-glaucoma therapy is known to be low even when compared with adherence to therapy for other chronic conditions. We performed a PubMed search to review evidence as to how adherence to and persistence with anti-glaucoma medications might be improved. Approaches to improving adherence include technological (such as using smart drop bottles or automated reminders) use of instillation aids, improving communication with patient education and improving tolerability of eye drop formulations. There is limited shortterm evidence that automated reminders can be effective and, unfortunately, instillation aids have not proved to be efficacious with respect to improving adherence. A range of factors have been identified which affect adherence and persistence, although only a multi-faceted approach has proven evidence of efficacy, compared to improved patient education alone. There is now a wider range of available preservative-free eye drops, which have been shown to be non-inferior in achieving IOP control, with fewer side effects and improved short-term adherence. Further studies relating to adherence are warranted, particularly given the projected increase in glaucoma prevalence worldwide.
\end{abstract}

Keywords: tolerability, ocular hypotensives, interventions, persistence, intraocular pressure

\section{Introduction}

The glaucomas form a heterogenous group of conditions that result in optic neuropathy with characteristic optic nerve head cupping and loss of visual field. ${ }^{1}$ Glaucoma is considered to be one of the most common causes of irreversible blindness worldwide, with nearly 80 million people estimated to be affected in 2020 , at least $10 \%$ of whom were classified as blind. ${ }^{1,2}$ Furthermore, due to the initial asymptomatic nature of most glaucoma, even studies in developed Western nations (where a degree of glaucoma screening is available) have revealed that up to half of all glaucoma cases remain undiagnosed. ${ }^{3-5}$

Primary open angle glaucoma (POAG) is the most common form of the condition, accounting for more than two-thirds of cases. ${ }^{6}$ Amongst the other types of glaucoma, primary angle closure glaucoma (PACG) represents the next most common cause and this has higher prevalence in East Asian countries. ${ }^{7}$ Most forms of glaucoma, including the vast majority of secondary glaucomas, are associated with an elevated intraocular pressure (IOP) as the major aetiological risk factor. Current treatments all target IOP and this remains the only modifiable
Correspondence: Ian Tapply

Department of Ophthalmology,

Addenbrooke's Hospital, Hills Road,

Cambridge, CB2 0QQ, UK

Tel +447810 583319

Email ian.tapply@nhs.net 
factor, for which there is evidence, that can stop or reduce the rate of visual deterioration, even in patients with apparently normal IOP at presentation. ${ }^{8-19}$ Despite IOP lowering, some patients can continue to experience worsening visual function, suggesting the presence of IOPindependent aetiological risk factors. ${ }^{14,20}$

Once diagnosed with glaucoma, patients should be offered lifelong control of IOP with monitoring of optic nerve appearance and visual function. ${ }^{21}$ The need for diagnosis and subsequent monitoring places a significant burden on both healthcare systems providing glaucoma services and on patients with ongoing hospital appointments and treatments. The burden of a glaucoma service is for a patient population where most individuals are asymptomatic but potentially at risk of functionally significant visual loss. When IOP lowering is indicated, options to achieve this include medical, laser and surgical modalities. Whilst the benefits of laser therapy in the form of selective laser trabeculoplasty has increasing evidence for use as an initial therapy for open angle glaucoma, topical medical therapy remains the most commonly utilised first-line treatment option at present. ${ }^{21,22}$

Topical medications are only suitable for patients who can regularly administer them or those who have others able to do so for them, such as family members or carers. Topical medications also carry a risk of local side effects, such as irritation, hyperaemia, dry eye, allergic/toxic conjunctivitis/keratitis, sub-conjunctival fibrosis, iris colour change, eyelash growth and/or orbital fat atrophy. Furthermore, the potential for systemic side effects should also be considered, particularly with $\beta$-blocker therapy. Administration of topical treatments entails a long-term commitment for the majority of patients with glaucoma requiring IOP lowering. Adherence, persistence and concordance with therapy require organisation and motivation to administer a preventative therapy in individuals who may be asymptomatic and appreciate no perceived benefit. Failure to take medications results in worse outcomes in patients with glaucoma and there is evidence to suggest that overall adherence with glaucoma therapy is typically poor when compared with adherence to medications for other systemic chronic conditions. ${ }^{23,24}$

The aim of this review was to summarise the available evidence regarding potential methods for the improvement of adherence to topical anti-glaucoma medication. The full assessment of anti-glaucoma medications administered by other routes was considered to be outside the scope of the review. Electronic searches relating to the improvement of adherence to topical anti-glaucoma therapies were made using PubMed (January 1979-January 2021). Initial search terms for the literature review included "topical", "glaucoma", "medication", "adherence" and "improve", which yielded 68 results. The literature search results were assessed for relevance and quality by the authors and papers deemed appropriate were included. Additionally, any further relevant papers of sufficient quality identified amongst the references were included in the review.

\section{Adherence}

Whilst adequate control of IOP is achievable in the majority of patients, topical ocular hypotensives can only achieve this if administered correctly, regularly and persistently. The nature of glaucoma as a chronic and initially asymptomatic condition almost certainly contributes to greater non-adherence and subsequently poorer visual outcomes. $^{23,25,26}$ Non-adherence is, however, a result of a complex series of factors, with one study identifying more than 70 barriers to adherence over four categories: regimen, individual patient factors, medical provider issues and situation factors. ${ }^{27,28}$ Additionally, there are cultural variances in such barriers to good adherence, as well as differences resulting from varying healthcare models. $^{29}$

The term "adherence" has replaced the more traditional term "compliance" over time; this reflects a change from the view of a prescription from a doctor as an instruction to be complied with, to recognising this as a joint decisionmaking process between patient and doctor. The term "concordance" has also been introduced into the overall approach to the prescribing and taking of medications, this being an agreement reached after "negotiation" between patient and clinician that respects the patient's beliefs and wishes. Use of the term "adherence" is considered to be a factual statement and nonjudgmental in tone, which is ideally achieved with "concordance". 30,31 Furthermore, the term "persistence" has been introduced, this describing the duration of medication use, from initiation to discontinuation. Persistence with therapy reflects the tolerability of the treatment to the patient, the desire of the patient to want therapy, in addition to the prescribing clinician's satisfaction with clinical effect and is, therefore, of significant importance in the management of a chronic condition such as glaucoma. ${ }^{32,33}$ In addition, there is the concept of "self-efficacy" in the management of chronic health conditions. "Self-efficacy" is defined as an individual's confidence regarding their capability of completing a task to 
achieve the desired outcome. ${ }^{34,35}$ If patients have higher "self-efficacy" with regards to performing certain behaviours, such as taking eye drops, they are more likely to complete those behaviours. For evidence-based therapy, ideal outcomes are most likely to be achieved with good concordance, adherence and persistence.

Given the multitude of influencing factors it is not realistic to achieve complete adherence to therapy in all patients all of the time. However, it is recognised that lower adherence to anti-glaucoma therapy leads to higher IOPs, greater fluctuation of IOP and consequently worsening of glaucomatous visual field defects. ${ }^{23,36-38}$ Despite this, there is evidence that a significant proportion of the patients who do not adhere to treatment do so within the first 6 months of initiating topical therapy, during a period when one might expect engagement with therapy to be at its best. ${ }^{24,39,40}$ More broadly, formally defining an adequate level of adherence with regard to topical antiglaucoma therapy has proved troublesome. An adherence rate of $80 \%$ may be considered acceptable for many systemic medications but there is no consensus regarding such a rate for ocular hypotensives. ${ }^{21}$ Furthermore, measurement of adherence to topical anti-glaucoma therapy has proven difficult because of the wide range in published adherence rates for similar populations. ${ }^{41}$ A significant factor in the assessment of adherence relates to the fact that measurement of adherence is problematic since study participation itself almost certainly influences participant behaviour (the Hawthorne effect). ${ }^{42}$ Use of IOP as an outcome measure for measuring adherence is problematic due to individual differences (types of glaucoma and diurnal variation), together with regression to the mean issues. ${ }^{43-46}$ Utilising ideal clinical outcomes of stable optic disc morphology and/or visual field defect stability as correlates of adherence is not feasible because measurement variability is high, pathological changes occur too slowly and these can occur despite adequate IOP lowering (eg that achieved surgically, without the need for adherent therapy). Measuring adherence has, therefore, been undertaken utilising a variety of methods, none of which has proved perfect. Several studies have used uptake of medication prescriptions, whereas others have used physicianreported or self-reported measures (eg questionnaires). ${ }^{47}$ The most accurate method of determining adherence is thought to be via electronic monitoring but this method is not without its own disadvantages. ${ }^{47-51}$

Additional problems with adherence research relate to study participant inclusion criteria. Several studies examining interventions to improve adherence to antiglaucoma medications have enrolled patients identified to be poorly adherent in an attempt to create the best conditions to measure greater effect size. ${ }^{52}$ Selection of poorly adherent patients has the risk of making findings nongeneralisable to all glaucoma patients, although it does of course target those most in need of support. With newly diagnosed glaucoma patients at the point of medication initiation, it remains difficult to identify those likely to be poorly adherent and more research is needed to help clinicians understand their patients better, identify those most likely to be poorly adherent and target support appropriately.

\section{Improving Adherence to Topical Glaucoma Therapy}

Given the high prevalence of glaucoma, visual loss secondary to the condition and the recognised suboptimal adherence and persistence rates in certain populations, strategies to improve adherence to glaucoma therapy continue to be of interest within the ophthalmological community. Approaches to the problem of non-adherence can be divided into technological (such as smart drop bottles or automated reminders), use instillation aids, improving communication with patient education and improving tolerability of eye drop formulations.

\section{Reminders}

A small number of studies have assessed the impact of providing regular reminders to patients. Using electronic monitoring of patients to measure adherence, Okele et al investigated the effect of telephone reminders in combination with an educational video, reminders on dosing-aid devices and review of individual barriers to adherence. Sixty-six US glaucoma patients taking a prostaglandin analogue, who had been recorded as taking $75 \%$ or fewer of their doses in the preceding 3 months, were randomised into a group with the intervention suite or no additional intervention. A significant rise in the mean number of taken doses, from $54 \%$ to $73 \%$, was found in the intervention group at a 3-month follow-up time-point, compared to no change in the control group; no corresponding fall in IOP was found ${ }^{43}$ In a similar prospective cohort study, Boland et al reported a rise in electronically monitored adherence from $53 \%$ to $64 \%$ in an intervention group also consisting of previously non-adherent US patients. Patients taking a once daily topical glaucoma medication 
were reminded to take their medication with either a text or voice message, with 38 patients in the intervention group and 32 in the control. However, in the latter study, the dropout rate was high in both groups, nearing $50 \%$ at the 3-month study follow-up visit. ${ }^{53}$

In a more recently published study from Singapore, the effect of a tele-reminder on patients taking three or more anti-glaucoma medications was assessed by Lai et al, using a self-reported measure of adherence (the Morisky adherence scale). In Lai et al's small study, 59 patients were randomised to one of 3 groups (a control group, a reference chart only group or a reference chart with telereminder group). Follow-up was only short term (6 weeks) and only the third group (with a reference chart and telereminder) experienced a small, but statistically significant, increase in adherence score, from 7.18 to $7.69(p=0.047){ }^{54}$ In conclusion, a few small studies have suggested that frequent reminders might increase adherence in the short term, although their efficacy in the longer term has not been assessed.

\section{Smart Drop Bottles}

As technology and patient familiarity with technology have developed, the potential for smart drop bottles to automate reminders for patients to administer medications and record delivered doses has grown. One group has recently outlined details of a smart bottle device which records drop administration and connects to a mobile phone application via Bluetooth to record the event. ${ }^{55}$ The smart bottle device has been reported to have an appropriate battery life of around 3 weeks for bilateral 3 times a day administration of topical medication, a $0 \%$ false positive rate and a $0 \%$ false negative rate if consecutive bottle squeezes are at least two seconds apart. The application enables reminders to be set by the patient, as well as administration data to be reviewed and reminders to be edited by authorised care-givers. Further studies are required to determine if smart bottle devices can improve adherence and persistence in the relevant patient cohort.

\section{Instillation Aids}

With advancing age being an important risk factor for most forms of glaucoma, many patients suffer reducing manual dexterity and grip strength throughout the course of their disease management. Since topical ocular medications require a specific technique for successful administration, there can be a physical barrier to adherence (unintentional), which a patient cannot overcome without aid from a carer or an instillation aid. ${ }^{56}$ One study found that one in five Scottish glaucoma patients prescribed topical medication reported difficulty in squeezing their eye drop bottle. ${ }^{57}$

Given the finding that patients often have physical difficulties with eye drop administration, there has been interest in the development of various instillation aids and a number of devices have now been available for over 30 years. ${ }^{58}$ One of the first instillation aids to have its effectiveness assessed was the Easidrop ${ }^{\circledR}$ device (Quoteforce, UK), which can be attached to a conventional eye drop bottle and placed against the orbital margins, aiming to keep the bottle tip away from the globe. It was reported that the proportion of patients who could successfully administer an eye drop on the first attempt rose from $20 \%$ to $87 \%$, although participants in the study were lying flat whilst administering the drops, an atypical positioning for many patients when administering their eye drops. ${ }^{57}$ Studies of two similar aids found no effect on IOP control a fortnight later in a small cohort of 32 Brazilian patients using the Eyedrop ${ }^{\circledR}$ device (Vanguard Design, Brazil) and, in a much larger randomised controlled trial (RCT) involving 652 Dutch patients, use of the Eyot $^{\circledR}$ device (Alcon Laboratories, USA) over a 6-month period was associated with reduced patient satisfaction and adherence compared to use of a dosing aid alone. ${ }^{59,60}$ A Canadian study of a further funnel-shaped device, designed to sit within the margins of the orbit, also returned disappointing results; the device scored lower on a subjective usability scale than administering the drops without the device and $71 \%$ of the 93 participants who completed the study did not wish to continue using it. ${ }^{61}$

There have been attempts to develop devices that offset the difficulties some patients experience due to a reduction in grip strength or manual dexterity. The Opticare ${ }^{\circledR}$ device (Cameron Graham, UK) encases the drop bottle to aid squeezing and the Opticare Arthro ${ }^{\circledR}$ (Cameron Graham, UK) features extended arms to further aid squeezing of the bottle for patients with severe arthritis. In the delivery of lubricating drops in 30 patients with rheumatoid arthritis, the Opticare ${ }^{\circledR}$ device was found to only be "impossible" or "very difficult" to use in three patients compared to a standard bottle which 15 patients found "impossible" or "very difficult" to use. ${ }^{57,62}$ Another approach has been the development of bottle devices that deliver a single drop on depression of a button; the upright eye drop bottle studied in the US delivered one drop on depressing a button and was designed to be used without the need 
for the patient to tilt their head back. The study of 40 US patients compared a standard bottle to the study device and found that patients used fewer drops with the study device, although there was no significant improvement in drop administration accuracy with the study device. ${ }^{63}$ Another study assessed a similar device designed specifically for use with a Xalatan ${ }^{\circledR}$ (latanoprost; Pfizer, USA) or Xalacom $^{\circledR}$ (latanoprost/timolol; Pfizer, USA) bottle; the Xal-Ease $^{\circledR}$ (Pfizer, USA) device was reported to reduce the need for help when administering drops and reduced bottle-tip contamination after 4 -week follow-up. ${ }^{64}$

Whilst laudable attempts to develop eye drop administration aid devices have taken a variety of approaches, there is no evidence that any specific device improves adherence in the administration of topical anti-glaucoma medications or result in improved IOP control. It has proven difficult to create an instillation aid that overcomes the reduction in dexterity and grip strength many patients experience, as they get older. Eye drop instillation aids are likely to provide a limited role in improving adherence and persistence for the whole glaucoma patient cohort, although they undoubtedly make drop administration easier for a subset of patients who have tried them with success.

\section{Communication and Education}

Many of the factors that contribute to poor adherence relate to patient knowledge of glaucoma, familiarity with treatment and broader beliefs; these are factors for which it is plausible that poor adherence might be ameliorated by improved or alternative methods of communication and education. The interplay between patient characteristics and factors relating to knowledge and education is complex, which makes identifying key individual factors and subsequently testing interventions to improve adherence very difficult. $^{27,28}$

Several studies have identified potential areas of focus for improved patient communication and education, across a range of cultural settings. In a study of 300 US glaucoma patients prescribed prostaglandin analogue monotherapy for newly diagnosed POAG, Friedman et al reported that the key aspect of patient education relating to adherence was ensuring awareness of the potential for future vision loss. ${ }^{65}$ In a qualitative (focus group and interview) study of 24 UK glaucoma patients treated for a minimum of a year, it was reported that a key motivating factor for antiglaucoma therapy adherence was fear of blindness, together with faith in drug efficacy. The UK study reviewed obstacles to adherence in patients with moderate or severe glaucoma who had been prescribed at least two topical anti-glaucoma medications. Multiple obstacles to adherence were identified, including poor education, lack of motivation, forgetfulness and practical issues relating to eye drop administration. ${ }^{27}$ More recently, a study of 317 Turkish glaucoma patients identified a significant difference in illness perception, such as an understanding of the consequences of glaucoma, between adherent and nonadherent groups. $^{66}$

Other studies have found evidence that patient knowledge of glaucoma can affect adherence. A study of 581 Korean glaucoma patients found that knowledge of glaucoma was the only factor associated with a patient's selfevaluation of compliance ("adherence"); forgetfulness being identified as the main reason for non-adherence. ${ }^{67}$ Rees et al assessed beliefs and adherence amongst white Americans, white Australians, African-Americans and Singaporeans of Chinese descent and reported higher selfreported adherence in the white Australian and white American groups. Additionally, beliefs regarding their glaucoma treatment were only predictive of adherence in the latter two groups of white Australians and white Americans. ${ }^{68}$ Rees et al went on to study 131 Australian glaucoma patients and identified $45 \%$ who reported some degree of non-adherence, of which $66.1 \%$ was unintentional, $16.9 \%$ intentional and $16.9 \%$ a combination. Nonadherers were younger, less likely to have non-ocular health conditions and reported lower belief in the necessity for eye drops for glaucoma. The degree of unintentional non-adherence was associated with lower belief in their necessity and the degree of intentional non-adherence was associated with concerns regarding the eye drops. ${ }^{42}$

Broader factors relating to patient education have been raised in other adherence research. A large study of Taiwanese glaucoma patients assessed persistence at a 2-year follow-up time-point in 3134 patients; only $24.2 \%$ had persisted with their anti-glaucoma medication. The authors of the Taiwanese study suggested that a good physician-patient relationship and patient education might play an important role in persistence with topical glaucoma medication. $^{69}$ A qualitative study of 33 UK glaucoma patients explored issues relating to non-adherence and identified two sub-themes: treatment schedule and patient factors. The authors of the UK study reported that possible side effects, inconvenience relating to treatment schedule and patient factors including memory, motivation and belief in treatment efficacy all had a potential effect on 
level of adherence. ${ }^{70}$ In a multi-centre, combined quantitative and qualitative questionnaire-based assessment of 145 Australian glaucoma patients, $69.7 \%$ of patients reported total adherence at a 2-week follow-up timepoint. The authors of the Australian study identified 4 factors significantly associated with non-adherence: difficulty applying drops, past or current diagnosis of depression, lower self-rating of memory and lower self-rated motivation score. The Australian patients' understanding of glaucoma, ethnicity and socioeconomic status was not found to have a statistically significant correlation with adherence. $^{71}$

Evidence for positive outcomes of interventions related to overcoming the known barriers to adherence is more limited. A large Dutch study published by Beckers et al, which utilised patient education within an RCT study of four intervention arms (mainly assessing the effect of an eye drop instillation aid), did not find that education alone led to improved adherence, measured by electronic monitoring. ${ }^{60}$ Another study evaluating the effectiveness of education provided within a nurse-led glaucoma monitoring clinic also provided no evidence that interventions focusing on education alone result in improved adherence with anti-glaucoma therapy. ${ }^{72}$ In contrast, Okeke et al found that a multi-faceted approach improved adherence (measured by electronic monitoring) at a 3-month followup time-point compared to no intervention in a cohort of US patients. ${ }^{43}$ Similarly a relatively large UK-based RCT found that an individualised patient care package improved prescription collection at 12 months, as well as significantly reducing IOP fluctuations and changes in clinical management at 24 months. In the latter study, Grey et al utilised an individualised care plan implemented by a glaucoma-trained nurse, this including an assessment of healthcare needs and beliefs, an educational session and a training session on eye drop instillation. ${ }^{73}$ In another, similar large UK-based RCT, Cate et al studied the effect of a novel intervention involving the provision of glaucoma education together with a motivational support package using behaviour change counselling. ${ }^{74}$ Cate et al studied patients starting monotherapy with travoprost and reported an unexpectedly high adherence rate for a control group of glaucoma patients undergoing standard care, such that it proved impossible to identify any improvement with the intervention. Of importance, however, was that the latter study demonstrated that provision of information, tailored to the individual patient, was inexpensive and was an intervention achieving high levels of patient satisfaction.

A study of 82 Swedish glaucoma patients measured adherence to a 3 times a day regimen of pilocarpine eye drops using a medication monitor. Norell reported a statistically significant reduction in missed doses and the proportion of time a dose was overdue in the intervention group, who had a 30-minute education and tailoring programme. ${ }^{75}$ In a 2013 review article, Waterman et al concluded there was some evidence that patient education married with more complex behavioural change interventions improved adherence to topical anti-glaucoma therapy. However, the available studies assessed in the review were of variable quality and, in the majority of patients, follow-up duration was short (less than 6 months). Additionally, the review reported there was weak evidence that glaucoma patients on simpler treatment regimens were more likely to adhere and persist with their anti-glaucoma therapy. Waterman et al highlighted the need for longer follow-up periods, standardised outcome measures and better reporting of studies in future adherence research. ${ }^{76}$

Many barriers to adherence relating to education, communication and patient beliefs have been identified but, despite the fact that they appear to be desirable to patients, there is little evidence that any interventions to target the known barriers result in improved adherence. The provision of an economically viable, multi-faceted and individually tailored support package would seem a plausible manner by which adherence and persistence with antiglaucoma therapy could be improved, given the likely interplay of multiple factors within each individual patient. However, further development and assessment of interventions to improve adherence are required before clinicians will know the best methods to implement.

\section{Preservative-Free Drops}

A major barrier to adherence and persistence is the development of medication side effects. Whilst most patients tolerate ocular hypotensive eye drops well, local sequelae to topical therapy can vary from minor irritation to significant allergic or toxic responses. ${ }^{21,77}$ The use of preservatives, in particular benzalkonium chloride (BAC), has been implicated in studies as a relatively frequent cause of ocular surface disease (OSD) in patients taking topical ocular hypotensives. ${ }^{77-86}$ Furthermore, a recent review confirmed that using preserved topical glaucoma medication was strongly associated with increased dry eye symptoms. ${ }^{87}$ A switch in therapy from a preserved to 
a preservative-free $(\mathrm{PF})$ regimen can be all that is required to improve tolerability and this has the potential to improve adherence and persistence for patients suffering with drop preservative-induced OSD.

In a large European survey study of 4107 patients, Pisella et al reported that the frequency of OSD symptoms related to the number of preservative-containing topical medications, that the preservative was responsible for poor tolerance and that this improved after a switch of therapy to PF preparations. ${ }^{84}$ Jaenen et al carried out another large European study of 9658 glaucoma patients investigating signs, rather than symptoms, of OSD and reported that the prevalence of adverse OSD signs (hyperaemia, superficial punctate keratitis, blepharitis, fluorescein-staining) was significantly more prevalent in patients administering preserved, rather than PF, topical medications. ${ }^{88}$ In another survey study of French glaucoma patients, Nordmann et al reported that $62 \%$ of the patients complained of at least one OSD side effect and $19 \%$ of at least 4 such side effects. ${ }^{89}$ Furthermore, Nordmann et al reported that patients dissatisfied with their medications visited their healthcare provider more frequently, an unwelcome effect in an era when many glaucoma services struggle with appointment backlogs. ${ }^{89},{ }^{90}$ Nordmann et al also reported that the side effects of burning, itching, dryness and redness were all associated with a reduced quality of life (QoL) score and the worsening QoL scores correlated with reduced adherence (measured by a simple questionnaire) ${ }^{89}$ As such, the link between drop tolerability and patient adherence or persistence has become recognised by clinicians, including within the European Glaucoma Society guidelines. ${ }^{91-94}$ More robust evidence and a quantification of effect relating to topical medication side effects and their effect on adherence, however, remains somewhat lacking. Despite the lack of evidence that preserved topical medications have a significant deleterious effect on adherence with therapy, common sense has prevailed and a useful range of PF topical therapies has become available. Preservative-free $\beta$-blockers (timolol, betaxolol and levobunolol), a miotic (pilocarpine), a carbonic anhydrase inhibitor (dorzolamide) and an $\alpha$-agonist (apraclonidine) have been available for many years, but it was only in 2008 that the first PF prostaglandin analogue, tafluprost (Saflutan ${ }^{\circledR}$, Santen Oy, Finland) became available. ${ }^{95}$

Following the introduction of PF tafluprost, PF latanoprost and PF bimatoprost have become available. A multitude of studies has been published comparing the efficacy and tolerability of the PF prostaglandin analogues in comparison with preserved preparations. In one large German multi-centre observational study involving 544 patients, PF tafluprost was prescribed as a substitution for various preserved fixed or non-fixed combinations, an add-on to existing combination therapy or as monotherapy in a newly initiated strategy; after 12 weeks, IOP was significantly reduced and there were fewer ocular adverse signs or symptoms. ${ }^{96}$ A meta-analysis of two phase IIIb clinical trials assessing 339 patients switching from preserved latanoprost to PF tafluprost similarly found a reduction in ocular signs and symptoms with unchanged IOP control, with $72 \%$ of the patients preferring the PF tafluprost compared with preserved latanoprost 12 weeks after the switch. ${ }^{97}$ Another multi-centre, open label study of PF tafluprost, conducted over a 12-week period, assessed 187 European patients who had been intolerant to preserved latanoprost or bimatoprost. When assessed at 12 weeks after switching to PF tafluprost there was improved IOP control, with $75 \%$ of the participants preferring the PF formulation. Although there was no formal assessment of adherence and the self-reporting method utilised was liable to reactivity bias, $84.1 \%$ of the participants reported being "very confident" that they would continue to be adherent with the PF formulation. In contrast, for the small cohort of patients who continued to have OSD symptoms with the PF tafluprost, only 30.6\% reported being "very confident" that they would continue with good adherence, potentially confirming the significant effect that OSD can have on adherence. ${ }^{98}$

One specific PF latanoprost (Monopost $^{\circledR}$, Thea Pharmaceuticals, UK) utilises a novel component (protriaxin) as a drug stability agent; the resulting solution being isotonic, with a neutral $\mathrm{pH}$, reducing the risk of the product causing stinging upon instillation, compared with many other topical ocular hypotensives. A large study of 1541 European (mainly Spanish) patients taking Monopost $^{\circledR}$ (PF latanoprost) found an increase in patient satisfaction with the novel PF formulation and the authors reported that the improved tolerability profile would be expected to improve adherence, although no assessment of adherence was actually carried out. ${ }^{99}$

A third widely available PF prostaglandin analogue is bimatoprost $0.03 \%$ (Lumigan $^{\circledR}$; Allergan, Ireland or Eyreida $^{\circledR}$; Aspire Pharma, UK). In a large, multi-centre, open-label, observational study, 1830 German patients with ocular hypertension or POAG were assessed following a switch from a variety of PF or preserved antiglaucoma medications to PF bimatoprost. The majority 
of participants warranted a switch in therapy due to inadequate IOP control and the majority of participants were administering PF topical ocular hypotensives prior to the study switch. The switch to PF bimatoprost was associated with improved IOP control and, methodology bias aside, physician-reported treatment compliance ("adherence") was stated to be better than $(48.7 \%)$ or equal to $(43.6 \%)$ that of prior treatment; most patients $(82 \%)$ were reported as "expected to continue" administering PF bimatoprost after the study period. ${ }^{100}$

Many published studies of PF ocular hypotensives have found that PF formulations are non-inferior to their preserved counterpart with respect to their IOP-lowering effect and invariably associated with less adverse signs and symptoms of OSD. In some studies, where attempts to assess adherence have been reported, both physician-reported and patient-reported adherence rates have improved when patients have been switched to PF formulations. However, there is a lack of long-term, quantitative data relating to the effect that the use of PF topical medications has on adherence and persistence. Given the proven improved tolerability of PF formulations in the treatment of glaucoma, further adherence research in this area is warranted.

\section{Changing Topical Medication Delivery Mechanisms}

Adherence to topical anti-glaucoma medications is likely to be better with simple therapeutic regimens, less frequent administration schedules and improved administration logistics and/or techniques.

\section{Bottles vs Single Dose Units (SDUs)}

The majority of topical ocular hypotensive medications are produced to be administered from either a bottle or a single dose unit (SDU). Although it has been suggested that patients might find administration of drops from SDUs more difficult than from conventional eye drop bottles, this was not confirmed in a comparative study involving 41 elderly Finnish patients; indeed, the authors reported that the patients, if anything, found the SDUs easier to use. ${ }^{101}$ Fortunately, the vast majority of currently prescribed topical anti-glaucoma medications are now available in either bottled or SDU formulations, even when PF, allowing patients an element of choice.

\section{Gel or Spray Formulations}

Preservative-free timolol $0.1 \%$ is available as a gel formulation (Nyogel $^{\circledR}$; Novartis, Switzerland), which is considered by some to be easier to administer than less viscous eye drops. Furthermore, the longer action of the gel formulation means that it is efficacious with only once daily dosing. ${ }^{102}$ The potential advantages of a gel formulation have been discussed by Negri et al following a review of 7 studies; the authors determined that the gel formulation had similar IOP-lowering efficacy to $\beta$-blocker solutions of higher concentrations, but was associated with improved QoL due to reduced symptoms of OSD. Although no assessment of adherence was reported, the authors commented that the once daily administration should improve adherence compared to the usual twice daily regimen recommended for other $\beta$-blocker formulations. ${ }^{103}$

Products delivering topical ocular therapy as a liposomal spray have been utilised for the administration of lubricant formulations and could provide an easier mechanism for self-delivery of medication in certain groups. ${ }^{56,104}$ However, research in this area with regard to glaucoma medications has been limited and currently there is no available ocular hypotensive in spray form. ${ }^{105,106}$

\section{Potential Methods for the Future}

Long-acting drug delivery systems have the potential to provide a more consistent level of IOP control, but by requiring less frequent administration also offer the opportunity to improve adherence and persistence with therapy. One group has described a hybrid dendrimer hydrogel/poly(lactic-co-glycolic acid) nanoparticle platform to deliver longer-acting topical ocular hypotensive therapy; however, the system remains experimental at present. ${ }^{107}$ Even longer-term delivery systems may hold some promise for improving adherence and avoiding traditional topical administration. For example, a sustained-release drug delivery system containing bimatoprost is currently undergoing investigation; an implant, administered intracamerally, involves a solid biodegradable polymer drug delivery system for slow, sustained drug release over a $4-6$-month period. ${ }^{108}$ Furthermore, the concept of using drug-eluting contact lenses to treat glaucoma and other ophthalmic conditions has been introduced and several groups are currently investigating the potential for this, at least for a subset of patients with glaucoma. ${ }^{109}$

\section{Conclusions}

Since barriers to adherence and persistence are multifaceted and highly variable between individuals, 
approaches to improve both adherence and persistence need to be multi-faceted and individually tailored. Key aspects, however, include schedule simplicity, ease of administration, minimisation of side effects and promotion of self-efficacy. It is important that prescribing ophthalmologists consider all known factors that can adversely reduce adherence given the known low levels of adherence and persistence with topical glaucoma medications.

There is evidence that the simpler the treatment regimen, the more likely patients are to be adherent. Additionally, given that age is a risk factor for many forms of glaucoma, it is likely that many patients will have other medications to remember to take and potentially have memory issues. Despite age-related comorbidities, there is no convincing evidence that older patients are less likely to be adherent to their antiglaucoma medication than younger patients. ${ }^{21}$ The technology to provide reminders is now available and in small studies has been shown to be effective in the short term. Further assessment of such interventions in the longer term is needed, but use of automated reminders almost certainly has the potential to improve adherence.

The challenges of facilitating eye drop administration in patients with reduced grip-strength and manual dexterity remain. Several devices have been trialled over the past three decades, although none has proven effective enough to be recommended for widespread usage. The trial data for such devices has failed to demonstrate that their use is associated with long-term improvement in adherence. For those patients who cannot self-administer topical medication and do not have access to carer support, alternative treatments such as selective laser trabeculoplasty or the potential sustained-release drug delivery systems of the future may prove more appropriate.

There has been a significant improvement in the range of PF topical glaucoma medications and these have been shown to be as effective at lowering IOP with a better side effect profile than their preserved counterparts. The role of preserved glaucoma eye drops in the aetiology of OSD has been recognised, highlighting the importance of prescribing $\mathrm{PF}$ alternatives. Given that the development of side effects is a significant factor in reducing tolerability (and hence adherence), the PF formulations have offered a useful alternative to aid improving both adherence and persistence. Dependent on cost and availability, preservative-free topical therapies are likely to continue to provide an increasing role in the medical management of glaucoma.
The promotion of self-efficacy in glaucoma patients could well be considered the most significant aspect for improving adherence and persistence, but perhaps the hardest to achieve. A range of factors related to reduced adherence with anti-glaucoma therapy has been identified. Limited evidence has suggested that a multi-faceted approach can improve adherence in the short and long term and improve IOP control. Confirming the efficacy of individual interventions is difficult, and further study is required in this area, both of individual interventions and personalised care plans.

A major problem persists regarding how best adherence can be measured since collecting data for conditions that are chronic, slowly progressive and require long-term follow-up is difficult. Although the use of multiple adherence measures might maximise precision, the effect that multiple measures have on participant behaviour and their potential reactivity effects might result in erroneous assessments. ${ }^{47}$ Until an accurate and reliable method of measuring adherence is established, sub-standard research findings are all that can be utilised to guide clinicians help their patients. The ultimate goal will be determining if improved adherence has an effect on clinically relevant outcome measures, such as longterm IOP control and visual field progression; future studies would be of greatest value if they can show such changes over a prolonged period of follow-up.

Given the projected increase in global prevalence of glaucoma, striving for an improvement of adherence and persistence to anti-glaucoma therapy should remain of key interest to the ophthalmic community.

\section{Abbreviations}

POAG, primary open angle glaucoma; PACG, primary angle closure glaucoma; IOP, intraocular pressure; CAIs, carbonic anhydrase inhibitors; RCT, randomised controlled trial; BAC, benzalkonium chloride; OSD, ocular surface disease; $\mathrm{PF}$, preservative-free; SDU, single dose unit.

\section{Disclosure}

The authors report no conflicts of interest with respect to this review.

\section{References}

1. Jonas JB, Aung T, Bourne RR, Bron AM, Ritch R, Panda-Jonas S. Glaucoma. Lancet. 2017;390(10108):2183-2193. doi:10.1016/S01406736(17)31469-1

2. Quigley HA, Broman AT. The number of people with glaucoma worldwide in 2010 and 2020. Br J Ophthalmol. 2006;90(3):262-267. doi:10.1136/bjo.2005.081224 
3. Wensor MD, McCarty CA, Stanislavsky YL, Livingston PM, Taylor HR. The prevalence of glaucoma in the melbourne visual impairment project. Ophthalmology. 1998;105(4):733-739. doi:10.1016/S0161-6420(98)94031-3

4. Mitchell P, Smith W, Attebo K, Healey PR. Prevalence of open-angle glaucoma in Australia. The Blue Mountains Eye Study. Ophthalmology. 1996;103(10):1661-1669. doi:10.1016/ s0161-6420(96)30449-1

5. Dielemans I, Vingerling JR, Wolfs RC, Hofman A, Grobbee DE, de Jong PT. The prevalence of primary open-angle glaucoma in a population-based study in The Netherlands. The Rotterdam Study. Ophthalmology. 1994;101(11):1851-1855. doi:10.1016/s01616420(94)31090-6

6. Kapetanakis VV, Chan MP, Foster PJ, Cook DG, Owen CG, Rudnicka AR. Global variations and time trends in the prevalence of primary open angle glaucoma (POAG): a systematic review and meta-analysis. $\mathrm{Br} \quad J$ Ophthalmol. 2016;100(1):86-93. doi:10.1136/bjophthalmol-2015-307223

7. Tham YC, Li X, Wong TY, Quigley HA, Aung T, Cheng CY. Global prevalence of glaucoma and projections of glaucoma burden through 2040: a systematic review and meta-analysis. Ophthalmology. 2014;121(11):2081-2090. doi:10.1016/j.ophtha. 2014.05.013

8. Collaborative Normal-Tension Glaucoma Study Group. The effectiveness of intraocular pressure reduction in the treatment of normal-tension glaucoma. Am J Ophthalmol. 1998;126 (4):498-505. doi:10.1016/s0002-9394(98)00272-4

9. The Advanced Glaucoma Intervention Study (AGIS): 7. The relationship between control of intraocular pressure and visual field deterioration. The AGIS investigators. Am J Ophthalmol. 2000;130(4):429-440. doi:10.1016/s0002-9394(00)00538-9

10. Anderson DR, Drance SM, Schulzer M; Collaborative NormalTension Glaucoma Study G. Natural history of normal-tension glaucoma. Ophthalmology. 2001;108(2):247-253. doi:10.1016/ s0161-6420(00)00518-2

11. Chauhan BC, Mikelberg FS, Artes PH, et al. Canadian Glaucoma Study: 3. Impact of risk factors and intraocular pressure reduction on the rates of visual field change. Arch Ophthalmol. 2010;128 (10):1249-1255. doi:10.1001/archophthalmol.2010.196

12. Chauhan BC, Mikelberg FS, Balaszi AG, et al. Canadian Glaucoma Study: 2. risk factors for the progression of open-angle glaucoma. Arch Ophthalmol. 2008;126 (8):1030-1036. doi:10.1001/archopht.126.8.1030

13. Drance S, Anderson DR, Schulzer M; Collaborative NormalTension Glaucoma Study G. Risk factors for progression of visual field abnormalities in normal-tension glaucoma. Am $J$ Ophthalmol. 2001;131(6):699-708. doi:10.1016/s0002-9394 (01)00964-3

14. Garway-Heath DF, Crabb DP, Bunce C, et al. Latanoprost for open-angle glaucoma (UKGTS): a randomised, multicentre, placebo-controlled trial. Lancet. 2015;385(9975):1295-1304. doi:10.1016/S0140-6736(14)62111-5

15. Heijl A, Leske MC, Bengtsson B, et al. Reduction of intraocular pressure and glaucoma progression: results from the early manifest glaucoma trial. Arch Ophthalmol. 2002;120(10):1268-1279. doi:10.1001/archopht.120.10.1268

16. Kass MA, Heuer DK, Higginbotham EJ, et al. The Ocular Hypertension Treatment Study: a randomized trial determines that topical ocular hypotensive medication delays or prevents the onset of primary open-angle glaucoma. Arch Ophthalmol. 2002;120(6):701-713. discussion 829-30. doi:10.1001/ archopht.120.6.701

17. Leske MC, Heijl A, Hussein M, et al. Factors for glaucoma progression and the effect of treatment: the early manifest glaucoma trial. Arch Ophthalmol. 2003;121(1):48-56. doi:10.1001/ archopht.121.1.48
18. Lichter PR, Musch DC, Gillespie BW, et al. Interim clinical outcomes in the Collaborative Initial Glaucoma Treatment Study comparing initial treatment randomized to medications or surgery. Ophthalmology. 2001;108(11):1943-1953. doi:10.1016/s01616420(01)00873-9

19. Nouri-Mahdavi K, Hoffman D, Coleman AL, et al. Predictive factors for glaucomatous visual field progression in the Advanced Glaucoma Intervention Study. Ophthalmology. 2004;111 (9):1627-1635. doi:10.1016/j.ophtha.2004.02.017

20. Anderson DR. Normal tension glaucoma S. Collaborative normal tension glaucoma study. Curr Opin Ophthalmol. 2003;14 (2):86-90. doi:10.1097/00055735-200304000-00006

21. Broadway DC, Cate H. Pharmacotherapy and adherence issues in treating elderly patients with glaucoma. Drugs Aging. 2015;32 (7):569-581. doi:10.1007/s40266-015-0282-9

22. Gazzard G, Konstantakopoulou E, Garway-Heath D, et al. Selective laser trabeculoplasty versus eye drops for first-line treatment of ocular hypertension and glaucoma (LiGHT): a multicentre randomised controlled trial. Lancet. 2019;393(10180):1505-1516. doi:10.1016/S0140-6736(18)322 $13-\mathrm{X}$

23. Sleath B, Blalock S, Covert D, et al. The relationship between glaucoma medication adherence, eye drop technique, and visual field defect severity. Ophthalmology. 2011;118(12):2398-2402. doi:10.1016/j.ophtha.2011.05.013

24. Yeaw J, Benner JS, Walt JG, Sian S, Smith DB. Comparing adherence and persistence across 6 chronic medication classes. J Manag Care Pharm. 2009;15(9):728-740. doi:10.18553/ jmcp.2009.15.9.728

25. Weinreb RN. Compliance with medical treatment of glaucoma. $J$ Glaucoma. 1992;1(2):134-136. doi:10.1097/00061198199201020-00012

26. Zimmerman TJ, Zalta AH. Facilitating patient compliance in glaucoma therapy. Surv Ophthalmol. 1983;28:252-258. doi:10.1016/0039-6257(83)90142-x

27. Lacey J, Cate H, Broadway DC. Barriers to adherence with glaucoma medications: a Qualitative Research Study. Eye. 2009;23(4):924-932. doi:10.1038/eye.2008.103

28. Tsai JC, McClure CA, Ramos SE, Schlundt DG, Pichert JW. Compliance barriers in glaucoma: a systematic classification. $J$ Glaucoma. 2003;12(5):393-398. doi:10.1097/00061198200310000-00001

29. Taylor SA, Galbraith SM, Mills RP. Causes of non-compliance with drug regimens in glaucoma patients: a Qualitative Study. J Ocul Pharmacol Ther. 2002;18(5):401-409. doi:10.1089/ 10807680260362687

30. Haynes RB, Ackloo E, Sahota N, McDonald HP, Yao X. Interventions for enhancing medication adherence. Cochrane Database Syst Rev. 2008;(2):CD000011. doi:10.1002/14651858. CD000011.pub3

31. Horne R. Compliance, adherence, and concordance: implications for asthma treatment. Chest. 2006;130(1Suppl):65S-72S. doi:10.1378/chest.130.1_suppl.65S

32. Deokule S, Sadiq S, Shah S. Chronic open angle glaucoma: patient awareness of the nature of the disease, topical medication, compliance and the prevalence of systemic symptoms. Ophthalmic Physiol Opt. 2004;24(1):9-15. doi:10.1046/j.14751313.2003.00155.x

33. Schwartz GF, Platt R. Measuring persistency and intraocular pressure-controlled days in patients receiving topical glaucoma medications. Am J Manag Care. 2002;8(10 Suppl): S278-80.

34. DeVellis B, DeVellis R. Handbook of Health Psychology. 2001.

35. Bandura A. Human agency in social cognitive theory. Paper presented at the 24th International Congress of Psychology; 1988; Sydney, Australia. 
36. Caprioli J, Coleman AL. Intraocular pressure fluctuation a risk factor for visual field progression at low intraocular pressures in the advanced glaucoma intervention study. Ophthalmology. 2008;115(7):1123-1129 e3. doi:10.1016/j.ophtha.2007.10.031

37. Rossi GC, Pasinetti GM, Scudeller L, Radaelli R, Bianchi PE. Do adherence rates and glaucomatous visual field progression correlate? Eur J Ophthalmol. 2011;21(4):410-414. doi:10.5301/ EJO.2010.6112

38. Stewart WC, Chorak RP, Hunt HH, Sethuraman G. Factors associated with visual loss in patients with advanced glaucomatous changes in the optic nerve head. Am J Ophthalmol. 1993;116 (2):176-181. doi:10.1016/s0002-9394(14)71282-6

39. Nordstrom BL, Friedman DS, Mozaffari E, Quigley HA, Walker AM. Persistence and adherence with topical glaucoma therapy. Am J Ophthalmol. 2005;140(4):598-606. doi:10.1016/j. ajo.2005.04.051

40. Patel SC, Spaeth GL. Compliance in patients prescribed eyedrops for glaucoma. Ophthalmic Surg. 1995;26(3):233-236.

41. Olthoff CM, Schouten JS, van de Borne BW, Webers CA. Noncompliance with ocular hypotensive treatment in patients with glaucoma or ocular hypertension an evidence-based review. Ophthalmology. 2005;112(6):953-961. doi:10.1016/j.ophtha.20 04.12 .035

42. Rees G, Leong O, Crowston JG, Lamoureux EL. Intentional and unintentional nonadherence to ocular hypotensive treatment in patients with glaucoma. Ophthalmology. 2010;117(5):903-908. doi:10.1016/j.ophtha.2009.10.038

43. Okeke CO, Quigley HA, Jampel HD, et al. Interventions improve poor adherence with once daily glaucoma medications in electronically monitored patients. Ophthalmology. 2009;116(12): 2286-2293. doi:10.1016/j.ophtha.2009.05.026

44. Ajit RR, Fenerty CH, Henson DB. Patterns and rate of adherence to glaucoma therapy using an electronic dosing aid. Eye. 2010;24 (8):1338-1343. doi:10.1038/eye.2010.27

45. Cate H, Broadway DC. Association between intraocular pressure and adherence: is there one? Eye. 2011;25(9):1238. doi:10.1038/ eye.2011.111

46. Ajit RR, Fenerty $\mathrm{CH}$, Henson DB. Response to cate and broadway. Eye. 2011;25(9):1238-1239. doi:10.1038/eye.2011.113

47. Cate H, Bhattacharya D, Clark A, Holland R, Broadway DC. A comparison of measures used to describe adherence to glaucoma medication in a randomised controlled trial. Clin Trials. 2015;12(6):608-617. doi:10.1177/1740774515592636

48. Friedman DS, Quigley HA, Gelb L, et al. Using pharmacy claims data to study adherence to glaucoma medications: methodology and findings of the Glaucoma Adherence and Persistency Study (GAPS). Invest Ophthalmol Vis Sci. 2007;48(11):5052-5057. doi:10.1167/iovs.07-0290

49. Hermann MM, Papaconstantinou D, Muether PS, Georgopoulos G, Diestelhorst M. Adherence with brimonidine in patients with glaucoma aware and not aware of electronic monitoring. Acta Ophthalmol. 2011;89(4):e300-5. doi:10.1111/ j.1755-3768.2010.02050.x

50. Schwartz GF. Compliance and persistency in glaucoma follow-up treatment. Curr Opin Ophthalmol. 2005;16(2):114-121. doi:10.1097/01.icu.0000156139.05323.26

51. Wilensky J, Fiscella RG, Carlson AM, Morris LS, Walt J. Measurement of persistence and adherence to regimens of IOP-lowering glaucoma medications using pharmacy claims data. Am J Ophthalmol. 2006;141(1 Suppl):S28-33. doi:10.10 16/j.ajo.2005.09.011

52. Glanz K, Beck AD, Bundy L, et al. Impact of a health communication intervention to improve glaucoma treatment adherence. Results of the interactive study to increase glaucoma adherence to treatment trial. Arch Ophthalmol. 2012;130(10):1252-1258. doi:10.1001/archophthalmol.2012.1607
53. Boland MV, Chang DS, Frazier T, Plyler R, Jefferys JL, Friedman DS. Automated telecommunication-based reminders and adherence with once-daily glaucoma medication dosing: the Automated Dosing Reminder Study. JAMA Ophthalmol. 2014;132(7):845-850. doi:10.1001/jamaophthalmol.2014.857

54. Lai $\mathrm{Y}, \mathrm{Wu} \mathrm{Y}, \mathrm{Chai} \mathrm{C}$, et al. The effect of patient education and telemedicine reminders on adherence to eye drops for glaucoma. Ophthalmol Glaucoma. 2020;3(5):369-376. doi:10.1016/j.ogla.20 20.05.005

55. Aguilar-Rivera M, Erudaitius DT, Wu VM, et al. Smart electronic eyedrop bottle for unobtrusive monitoring of glaucoma medication adherence. Sensors (Basel). 2020;20(9):2570. doi:10.3390/ s20092570

56. Davies I, Williams AM, Muir KW. Aids for eye drop administration. Surv Ophthalmol. 2017;62(3):332-345. doi:10. 1016/j.survophthal.2016.12.009

57. Winfield AJ, Jessiman D, Williams A, Esakowitz L. A study of the causes of non-compliance by patients prescribed eyedrops. Br J Ophthalmol. 1990;74(8):477-480. doi:10.1136/bjo.74.8. 477

58. Rivers PH. Compliance aids-do they work? Drugs Aging. 1992;2 (2):103-111. doi:10.2165/00002512-199202020-00004

59. Junqueira DM, Lopes FS, de Souza FC, Dorairaj S, Prata TS. Evaluation of the efficacy and safety of a new device for eye drops instillation in patients with glaucoma. Clin Ophthalmol. 2015;9:367-371. doi:10.2147/opth.S78743

60. Beckers HJ, Webers CA, Busch MJ, Brink HM, Colen TP, Schouten JS. Adherence improvement in Dutch glaucoma patients: a randomized controlled trial. Acta Ophthalmol. 2013;91(7):610-618. doi:10.1111/j.1755-3768.2012.02571.x

61. Salyani A, Birt C. Evaluation of an eye drop guide to aid self-administration by patients experienced with topical use of glaucoma medication. Can J Ophthalmol. 2005;40(2):170-174. doi:10.1016/s0008-4182(05)80028-6

62. Averns H, Hall J, Webley M. Role of opticare eye drop delivery system in patients with rheumatoid arthritis. J Rheumatol. 1999;26(12):2615-2618.

63. Davies IJ, Brown NH, Wen JC, et al. An upright eyedrop bottle: accuracy, usage of excess drops, and contamination compared to a conventional bottle. Clin Ophthalmol. 2016;10:1411-1417. doi:10.2147/opth.S104751

64. Nordmann JP, Baudouin C, Bron A, et al. Xal-Ease: impact of an ocular hypotensive delivery device on ease of eyedrop administration, patient compliance, and satisfaction. Eur J Ophthalmol. 2009;19(6):949-956. doi:10.1177/112067210901900609

65. Friedman DS, Hahn SR, Gelb L, et al. Doctor-patient communication, health-related beliefs, and adherence in glaucoma results from the Glaucoma Adherence and Persistency Study. Ophthalmology. 2008;115(8):1320-7, 1327.e1-3. doi:10.1016/j. ophtha.2007.11.023

66. Guven S, Koylu MT, Mumcuoglu T. Adherence to glaucoma medication, illness perceptions, and beliefs about glaucoma: attitudinal perspectives among Turkish population. Eur J Ophthalmol. 2020;5. doi:10.1177/1120672120901687

67. Park MH, Kang KD, Moon J. Noncompliance with glaucoma medication in Korean patients: a Multicenter Qualitative Study. Jpn J Ophthalmol. 2013;57(1):47-56. doi:10.1007/s10384-0120188-6

68. Rees G, Chong XL, Cheung CY, et al. Beliefs and adherence to glaucoma treatment: a comparison of patients from diverse cultures. J Glaucoma. 2014;23(5):293-298. doi:10.1097/IJG.0b $013 \mathrm{e} 3182741 \mathrm{flc}$

69. Hwang DK, Liu CJ, Pu CY, Chou YJ, Chou P. Persistence of topical glaucoma medication: a Nationwide Population-Based Cohort Study in Taiwan. JAMA Ophthalmol. 2014;132 (12):1446-1452. doi:10.1001/jamaophthalmol.2014.3333 
70. McDonald S, Ferguson E, Hagger MS, Foss AJE, King AJ. A theory-driven qualitative study exploring issues relating to adherence to topical glaucoma medications. Patient Prefer Adherence. 2019;13:819-828. doi:10.2147/ppa.S174922

71. Spencer SKR, Shulruf B, McPherson ZE, et al. Factors affecting adherence to topical glaucoma therapy: a Quantitative and Qualitative Pilot Study analysis in Sydney, Australia. Ophthalmol Glaucoma. 2019;2(2):86-93. doi:10.1016/j.ogla. 2019.01.006

72. Sheppard J, Warner J, Kelley K. An evaluation of the effectiveness of a nurse-led glaucoma monitoring clinic. Ophthalmic Nurs. 2003;7:15-21.

73. Gray TA, Fenerty C, Harper R, et al. Individualised patient care as an adjunct to standard care for promoting adherence to ocular hypotensive therapy: an exploratory randomised controlled trial. Eye. 2012;26(3):407-417. doi:10.1038/eye.2011.269

74. Cate H, Bhattacharya D, Clark A, Fordham R, Holland R, Broadway DC. Improving adherence to glaucoma medication: a randomised controlled trial of a patient-centred intervention (The Norwich Adherence Glaucoma Study). BMC Ophthalmol. 2014;14(1):32. doi:10.1186/1471-2415-14-32

75. Norell SE. Improving medication compliance: a randomised clinical trial. $B r$ Med J. 1979;2(6197):1031-1033. doi:10.1136/ bmj.2.6197.1031

76. Waterman H, Evans JR, Gray TA, Henson D, Harper R. Interventions for improving adherence to ocular hypotensive therapy. Cochrane Database Syst Rev. 2013;(4):Cd006132. doi:10.1002/14651858.CD006132.pub3

77. Servat JJ, Bernardino CR. Effects of common topical antiglaucoma medications on the ocular surface, eyelids and periorbital tissue. Drugs Aging. 2011;28(4):267-282. doi:10.2165/11588830000000000-00000

78. Dogan AS, Orhan M, Soylemezoglu F, Irkec M, Bozkurt B. Effects of topical antiglaucoma drugs on apoptosis rates of conjunctival epithelial cells in glaucoma patients. Clin Exp Ophthalmol. 2004;32 (1):62-66. doi:10.1046/j.1442-9071.2003.00760.x

79. Furrer P, Mayer JM, Plazonnet B, Gurny R. Ocular tolerance of absorption enhancers in ophthalmic preparations. AAPS PharmSci. 2002;4(1):E2. doi:10.1208/ps040102

80. Ishibashi T, Yokoi N, Kinoshita S. Comparison of the short-term effects on the human corneal surface of topical timolol maleate with and without benzalkonium chloride. J Glaucoma. 2003;12 (6):486-490. doi:10.1097/00061198-200312000-00008

81. Manni G, Centofanti M, Oddone F, Parravano M, Bucci MG. Interleukin-1beta tear concentration in glaucomatous and ocular hypertensive patients treated with preservative-free nonselective beta-blockers. Am J Ophthalmol. 2005;139(1):72-77. doi:10. 1016/j.ajo.2004.08.028

82. Nenciu A, Stefan C, Ardelean C. [Structural and immunohistochemical changes of conjunctiva induced by topical glaucoma medication]. Oftalmologia. 2004;48(1):35-42. Tratamentul topic antiglaucomatos-modificarile conjunctivale structurale si imunohitochimice. Portuguese.

83. Pisella PJ, Debbasch C, Hamard P, et al. Conjunctival proinflammatory and proapoptotic effects of latanoprost and preserved and unpreserved timolol: an ex vivo and in vitro study. Invest Ophthalmol Vis Sci. 2004;45(5):1360-1368. doi:10.1167/ iovs.03-1067

84. Pisella PJ, Pouliquen P, Baudouin C. Prevalence of ocular symptoms and signs with preserved and preservative free glaucoma medication. Br J Ophthalmol. 2002;86(4):418-423. doi:10.1136/ bjo.86.4.418

85. Martone G, Frezzotti P, Tosi GM, et al. An in vivo confocal microscopy analysis of effects of topical antiglaucoma therapy with preservative on corneal innervation and morphology. Am J Ophthalmol. 2009;147(4):725-735.e1. doi:10.1016/j.ajo.2008.10.019
86. Iester M, Oddone F, Fogagnolo P, Frezzotti P, Figus M. Changes in the morphological and functional patterns of the ocular surface in patients treated with prostaglandin analogues after the use of TSP $\quad 0.5 \%{ }^{\circledR}$ preservative-free eyedrops: a Prospective, Multicenter Study. Ophthalmic Res. 2014;51(3):146-152. doi: $10.1159 / 000357100$

87. Asiedu K, Abu SL. The impact of topical intraocular pressure lowering medications on the ocular surface of glaucoma patients: a review. J Curr Ophthalmol. 2019;31(1):8-15. doi:10.1016/j. joco.2018.07.003

88. Jaenen N, Baudouin C, Pouliquen P, Manni G, Figueiredo A, Zeyen T. Ocular symptoms and signs with preserved and preservative-free glaucoma medications. Eur $J$ Ophthalmol. 2007;17(3):341-349. doi:10.1177/112067210701700311

89. Nordmann JP, Auzanneau N, Ricard S, Berdeaux G. Vision related quality of life and topical glaucoma treatment side effects. Health Qual Life Outcomes. 2003;1(1):75. doi:10.1186/ 1477-7525-1-75

90. Broadway DC, Tibbenham K. Tackling the NHS glaucoma clinic backlog issue. Eye. 2019;33(11):1715-1721. doi:10.1038/s41433019-0468-1

91. European Glaucoma Society. European glaucoma society terminology and guidelines for glaucoma, 4th edition - chapter 3: treatment principles and options supported by the EGS foundation: part 1: foreword; introduction; glossary; chapter 3 treatment principles and options. Br J Ophthalmol. 2017;101(6):130-195. doi:10.1136/bjophthalmol-2016-EGSguideline.003

92. Kaštelan S, Tomić M, Metež Soldo K, Salopek-Rabatić J. How ocular surface disease impacts the glaucoma treatment outcome. Biomed Res Int. 2013;2013:696328. doi:10.1155/ 2013/696328

93. Reardon G, Kotak S, Schwartz GF. Objective assessment of compliance and persistence among patients treated for glaucoma and ocular hypertension: a systematic review. Patient Prefer Adherence. 2011;5:441-463. doi:10.2147/PPA.S23780

94. Zimmerman TJ, Hahn SR, Gelb L, Tan H, Kim EE. The impact of ocular adverse effects in patients treated with topical prostaglandin analogs: changes in prescription patterns and patient persistence. J Ocul Pharmacol Ther. 2009;25(2):145-152. doi:10.1089/jop.2008.0072

95. Uusitalo H, Kaarniranta K, Ropo A. Pharmacokinetics, efficacy and safety profiles of preserved and preservative-free tafluprost in healthy volunteers. Acta Ophthalmol. 2008;86(s242):7-13. doi:10.1111/j.1755-3768.2008.01380.x

96. Hommer A, Mohammed Ramez O, Burchert M, Kimmich F. IOPlowering efficacy and tolerability of preservative-free tafluprost $0.0015 \%$ among patients with ocular hypertension or glaucoma. Curr Med Res Opin. 2010;26(8):1905-1913. doi:10.1185/ 03007995.2010.492030

97. Uusitalo H, Egorov E, Kaarniranta K, Astakhov Y, Ropo A. Benefits of switching from latanoprost to preservative-free tafluprost eye drops: a meta-analysis of two Phase IIIb clinical trials. Clin Ophthalmol. 2016;10:445-454. doi:10.2147/opth.S91402

98. García-Feijoo J, Muñoz-Negrete FJ, Hubatsch DA, Rossi GC. Efficacy and tolerability of benzalkonium chloride-free travoprost in glaucoma patients switched from benzalkonium chloride-preserved latanoprost or bimatoprost. Clin Ophthalmol. 2016;10:2085-2091. doi:10.2147/opth.S112711

99. Muñoz Negrete FJ, Lemij HG, Erb C. Switching to preservative-free latanoprost: impact on tolerability and patient satisfaction. Clin Ophthalmol. 2017;11:557-566. doi:10.2147/ opth.S126042

100. Pillunat LE, Eschstruth P, Häsemeyer S, et al. Preservative-free bimatoprost $0.03 \%$ in patients with primary open-angle glaucoma or ocular hypertension in clinical practice. Clin Ophthalmol. 2016;10:1759-1765. doi:10.2147/opth.S103084 
101. Parkkari M, Latvala T, Ropo A. Handling test of eye drop dispenser-comparison of unit-dose pipettes with conventional eye drop bottles. J Ocul Pharmacol Ther. 2010;26(3):273-276. doi:10.1089/jop.2009.0111

102. Lazreg S, Merad Z, Nouri M, et al. Efficacy and safety of preservative-free timolol $0.1 \%$ gel in open-angle glaucoma and ocular hypertension in treatment-naïve patients and patients intolerant to other hypotensive medications. J Fr Ophtalmol. 2018;41 (10):945-954. doi:10.1016/j.jfo.2018.04.012

103. Negri L, Ferreras A, Iester M. Timolol $0.1 \%$ in glaucomatous patients: efficacy, tolerance, and quality of life. $J$ Ophthalmol. 2019;2019:4146124. doi:10.1155/2019/4146124

104. Craig JP, Purslow C, Murphy PJ, Wolffsohn JS. Effect of a liposomal spray on the pre-ocular tear film. Cont Lens Anterior Eye. 2010;33(2):83-87. doi:10.1016/j.clae.2009.12.007

105. Doe EA, Campagna JA, Dirhs MS, Johnson AJ. Timolol 0.5\% spray vs. timolol $0.5 \%$ drops for the control of intraocular pressure. Am Acad Ophthalmol. 1997;196.
106. Halberg GP, Kelly SE, Morrone M. Drug delivery systems for topical ophthalmic medication. Ann Ophthalmol. 1975;7(9):11991204, 1207-9.

107. Yang H, Leffler CT. Hybrid dendrimer hydrogel/poly(lactic-coglycolic acid) nanoparticle platform: an advanced vehicle for topical delivery of antiglaucoma drugs and a likely solution to improving compliance and adherence in glaucoma management. J Ocul Pharmacol Ther. 2013;29(2):166-172. doi:10.1089/ jop.2012.0197

108. Shirley M. Bimatoprost implant: first approval. Drugs Aging. 2020;37(6):457-462. doi:10.1007/s40266-020-00769-8

109. Toffoletto N, Saramago B, Serro AP. Therapeutic ophthalmic lenses: a review. Pharmaceutics. 2021;13(1):36. doi:10.3390/ pharmaceutics 13010036
Patient Preference and Adherence

\section{Publish your work in this journal}

Patient Preference and Adherence is an international, peer-reviewed, open access journal that focusing on the growing importance of patient preference and adherence throughout the therapeutic continuum. Patient satisfaction, acceptability, quality of life, compliance, persistence and their role in developing new therapeutic modalities and compounds to optimize clinical outcomes for existing disease

\section{Dovepress}

states are major areas of interest for the journal. This journal has been accepted for indexing on PubMed Central. The manuscript management system is completely online and includes a very quick and fair peer-review system, which is all easy to use. Visit http:// www.dovepress.com/testimonials.php to read real quotes from published authors. 